\title{
literature report
}

\section{A novel lectin in the secretory pathway}

\author{
An elegant mechanism for \\ glycoprotein elimination
}

How important can sugars be? Sure, glycoproteins need their glycans during synthesis for proper folding: the sugar chain increases solubility and prevents aggregation, and it mediates interactions with various proteins. On the other hand, so many different glycans exist on glycoproteins that it is difficult to imagine that each would have a specific function. Still, now and again, a new protein is identified that interacts with a particular carbohydrate chain, and that turns out to be crucial for a particular stage in the biosynthesis and maturation of glycoproteins. Will there be many, or do we have only a few? Whichever the answer, glycobiology is celebrating a certain revival.

The first step of $\mathrm{N}$-linked glycosylation is highly conserved amongst eukaryotic organisms: the $\mathrm{Glc}_{3} \mathrm{Man}_{9} \mathrm{GlcNAc}_{2}$ glycan chain is co-translationally attached to the Asn residue in the consensus motif Asn-X-Ser/Thr (Kornfeld and Kornfeld, 1985). Immediately after attachment, monosaccharides are removed one by one (Figure 1), only to prepare the glycan for the later addition of other monosaccharides. This apparently futile sequence of events is a consequence of the necessary signaling to glycan-specific lectins with various gate-keeper functions in the secretory pathway (Helenius and Aebi, 2001).

Lectins are defined as non-enzymatic, sugar-binding proteins that lack enzymatic activity towards carbohydrates. Up to now, only four lectins had been identified early in the secretory pathway, each with specific glycan recognition, and each with a specific function. Calnexin and calreticulin act as molecular chaperones in the endoplasmic reticulum (ER; Ellgaard et al.,

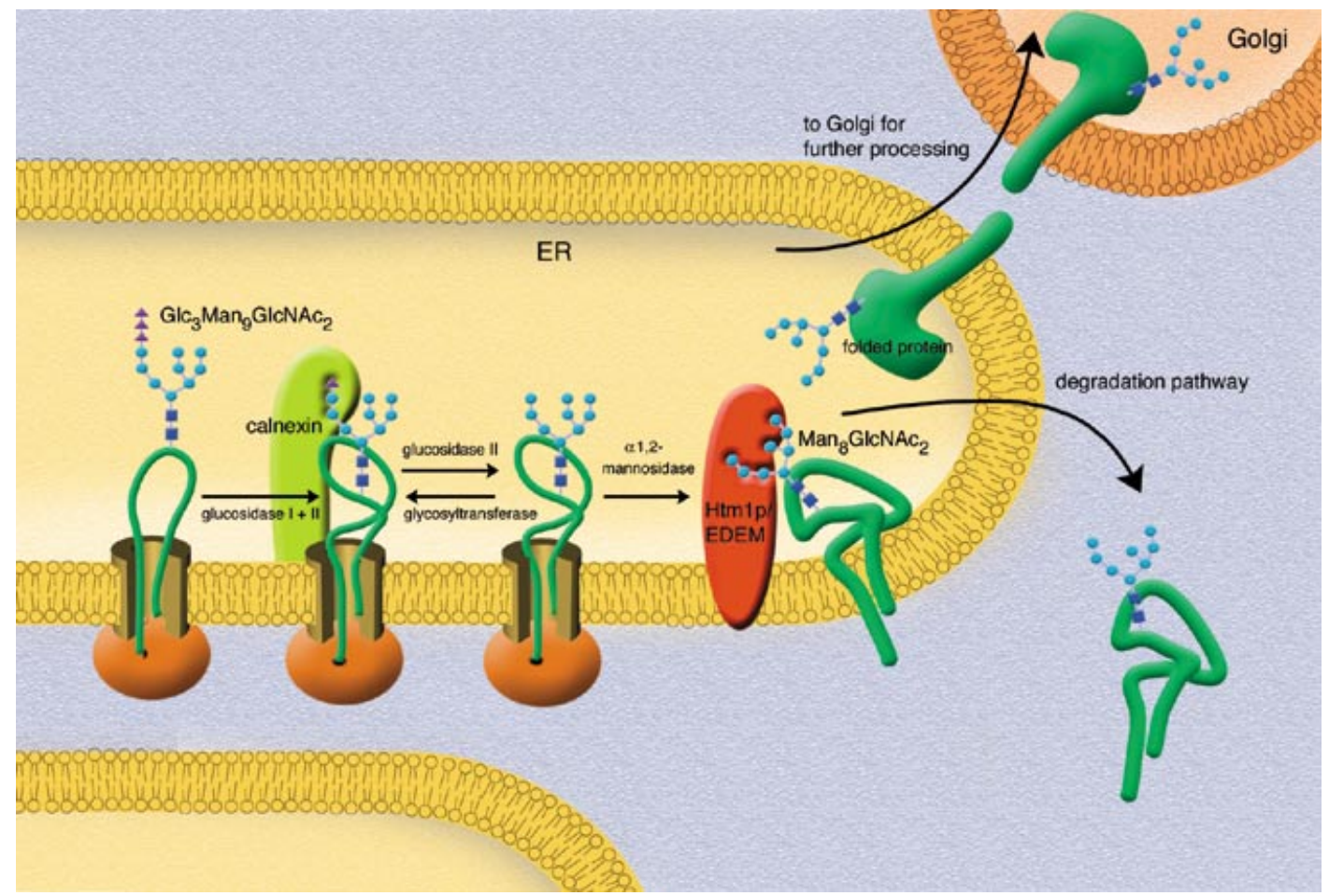

Fig. 1. Modifications of the N-linked glycan on proteins. Glycans are attached as the high mannose $\mathrm{Glc}_{3} \mathrm{Man}_{9} \mathrm{GlcNAc}_{2}$ chain. Immediately after attachment to the protein, the first glucose residue (triangle) is removed by glucosidase I, the second and third by glucosidase II. The third glucose can be reattached by a glucosyltranferase that recognizes only misfolded and unfolded proteins (Parodi, 2000; Helenius and Aebi, 2001). Calnexin and its soluble family member calreticulin (not depicted) associate with the monoglucose chain to retain immature glycoproteins in the ER, to allow folding to proceed, and to prevent release into the secretory pathway (Helenius et al., 1997; Parodi, 2000; Helenius and Aebi, 2001). The ER $\alpha 1,2$-mannosidase removes a single mannose, resulting in $\mathrm{Glc}_{0-3} \mathrm{Man}_{8} \mathrm{GlcNAc}_{2}$, before transport of the properly folded protein to the Golgi complex where further processing occurs. The Man 8 glycan, containing a yet unknown number of glucose residues, is recognized by Htm1p/EDEM and targeted for degradation. 


\section{literature report}

2000; Parodi, 2000), ERGIC-53 functions as a cargo receptor for transport from the ER to the intermediate compartment between the ER and the Golgi complex (ERGIC; Hauri et al., 2000), and VIP36 may function as a cargo receptor within the cis-Golgi (Fiedler et al., 1994). The presence of a fifth lectin, which targets proteins with an attached $\mathrm{Glc}_{0-3} \mathrm{Man}_{8} \mathrm{GlcNAc}_{2}$ for degradation, was suggested by several reports (Su et al., 1993; Liu et al., 1997; Jakob et al., 1998; Fagioli and Sitia, 2001). In 1998, Jakob et al. published a detailed study in which they showed that, in Saccharomyces cerevisiae, specifically the $\mathrm{Man}_{8} \mathrm{GlcNAc}_{2}$ intermediate allows rapid degradation of the protein to which it is attached (mutant carboxypeptidase $\mathrm{Y}$ in this case). This and the other reports prompted the speculation that an ER-localized lectin recognizing $\mathrm{Man}_{8} \mathrm{GlcNAc}_{2}$ glycans should be responsible for targeting misfolded and unfolded proteins to the proteasome for degradation.

And indeed, three papers now report the identification of $\alpha 1,2$-mannosidase-like proteins in $S$. cerevisiae and in mouse cells. These two proteins are homologous to one another and lack enzymatic mannosidase activity, suggesting that they are mannose-binding lectins (Hosokawa et al., 2001; Jakob et al., 2001; Nakatsukasa et al., 2001). A thorough biochemical study from the group of Nagata (Hosokawa et al., 2001) shows that the mouse protein EDEM has no mannosidase activity, it localizes to the ER, and it is upregulated upon ER stress. Overexpression of this protein resulted in increased degradation of misfolded $\alpha 1$-antitrypsin, but not of a non-glycosylated protein. As EDEM co-immunoprecipitates with misfolded protein, its role in degradation is more than suggestive. The presence of residues crucial for mannose binding completed the picture of EDEM as a mannose-binding lectin important for ER-associated degradation.

The group of Aebi (Jakob et al., 2001) reached similar conclusions about the $\mathrm{Htm} 1$ protein by different means. Jakob et al. identified the yeast $\mathrm{Htm} 1$ protein via a search for mannosidase homologs. They then used mostly genetic strategies to demonstrate that deletion of the protein from a yeast cell stabilizes glycoproteins but not a non-glycosylated protein. The results of the $h t m 1$ deletion were similar to the consequences of gene deletions that prevented the formation of a Man intermediate via a defect in either biosynthesis or trimming. The authors therefore suggest that Htm1 $\mathrm{p}$ acts through $\mathrm{Man}_{8}$.

The third report, by the group of Endo (Nakatsukasa et al., 2001), describes the identification of the yeast Mnl1 protein, which is identical to $\mathrm{Htm} 1 \mathrm{p}$. The experiments were similar to those of Hosokawa et al., but were performed in S. cerevisiae.

Newly synthesized proteins may reside in the ER for a long time, and folding intermediates must be distinguished from misfolded proteins and removed. Both may be associated with calnexin and calreticulin, which retain them in the ER, but at some point the decision for degradation must be made for proteins that will never reach a properly folded conformation. A specific signal for degradation is needed at this stage. Glycan trimming and the subsequent recognition of particular glycans have been suggested to act as a timer for degradation (Su et al., 1993; Helenius et al., 1997). \&1,2-mannosidase, which removes one mannose from $\mathrm{Man}_{9}$, apparently acts slowly, leaving sufficient time for folding. If a protein folds extremely slowly or into the wrong conformation, it ultimately reaches the Man $_{8}$ state that targets it for degradation. The Man $_{8}$-related literature indicates degradation periods of hours, compatible with the timer-hypothesis. We cannot, however, assume this mechanism to be simply time-dependent. The normal folding rates of proteins are highly variable, and the $\alpha 1,2$-mannosidase may remove mannose groups on different glycans at rates that differ depending on factors such as accessibility.

Ignored in many papers dealing with ER-associated degradation is the substantial amount of breakdown of nascent chains, already during protein synthesis. Hosokawa and colleagues show that ${ }^{35} \mathrm{~S}$ metabolic glycoprotein labeling of newly synthesized proteins (including EDEM) is strongly increased when protein degradation is inhibited (Hosokawa et al., 2001), suggesting a co-translational effect of the inhibitors. Mannosidase inhibition, which prevents removal of the ninth mannose residue, and hence the formation of the Man $_{8}$ glycan, also increased labeling, indicating an at least partially co-translational degradation mediated by mannose trimming. Proteasome inhibitors only mildly inhibited degradation induced by overexpression of EDEM. Thus, an additional, alternative degradation pathway is likely to exist. Contrasting with the timer hypothesis, which requires slow mannosidase activity, co-translational degradation mediated by the $\mathrm{Man}_{8}$ lectin must be rapid, taking place within the minutes it takes to synthesize a protein of average size. Since EDEM contains five $\mathrm{N}$-linked glycans, it may be subject to the same mannose-mediated control as the proteins it regulates.

The argument for $\mathrm{Man}_{8}$-lectin triggering protein degradation is very convincing, and $\mathrm{Htm} 1 \mathrm{p} / \mathrm{EDEM}$ seems to play a role in this process. On the other hand, Man $_{8}$ cannot be necessary or sufficient. Alternative pathways of glycan trimming may exist in different cell types and species (Herscovics, 1999), and many glycoproteins that move successfully to the Golgi from the ER will have had a $\mathrm{Man}_{8}$ intermediate. Perhaps the enzyme that checks the conformational quality of proteins earlier in the ER, the UDP-glucose:glycoprotein glucosyltransferase (Parodi, 2000), attaches a glucose to the $\mathrm{Man}_{8}$ glycan as well, and provides the specific signal for degradation. This would require $\mathrm{Htm} 1 \mathrm{p} / \mathrm{EDEM}$ to recognize only $\mathrm{Glc}_{1} \mathrm{Man}_{8}$ glycans and not any other $\operatorname{Man}_{8}$ glycans. An alternative scenario would predict that $\mathrm{Htm} 1 \mathrm{p} / \mathrm{EDEM}$ is not purely a lectin, but recognizes misfolded protein stretches as well.

Now that one lectin with a role in targeting proteins for degradation has been identified, it is tempting to speculate that more will follow. Candidates are lectins recognizing the $\mathrm{Man}_{9}$ or $\mathrm{Man}_{5}$ intermediate, alternative $\mathrm{Man}_{8}$ forms, and perhaps even every other common intermediate in the trimming pathway. The papers on Htm $1 \mathrm{p} / \mathrm{Mnl} 1 \mathrm{p}$ and EDEM signify only the next step in the long, hard search for the diverse roles of sugars in cell biology.

\section{Acknowledgements}

I thank Peter van der Sluijs for critically reading the manuscript, and members of my group for support and discussions.

\section{References}

Ellgaard, L., Molinari, M. and Helenius, A. (2000) Setting the standards: Quality control in the secretory pathway. Science, 286, 1882-1888.

Fagioli, C. and Sitia, R. (2001) Glycoprotein quality control in the endoplasmic reticulum. J. Biol. Chem., 276, 12885-12892. 


\section{literature report}

Fiedler, K., Parton, R.G., Kellner, R., Etzold, T. and Simons, K. (1994) VIP36, a novel component of glycolipid rafts and exocytic carrier vesicles in epithelial cells. EMBO J., 13, 1729-1740.

Hauri, H., Appenzeller, C., Kuhn, F. and Nufer, O. (2000) Lectins and traffic in the secretory pathway. FEBS Lett., 476, 32-37.

Helenius, A. and Aebi, M. (2001) Intracellular functions of N-linked glycans. Science, 291, 2364-2369.

Helenius, A., Trombetta, E.S., Hebert, D.N. and Simons, J.F. (1997) Calnexin, calreticulin and the folding of glycoproteins. Trends Cell Biol., 7, 193-200.

Herscovics, A. (1999) Importance of glycosidases in mammalian glycoprotein biosynthesis. Biochim. Biophys. Acta, 1473, 96-107.

Hosokawa, N., Wada, I., Hasegawa, K., Yorihuzi, T., Tremblay, L.O., Herscovics, A. and Nagata, K. (2001) A novel ER $\alpha$-mannosidase-like protein accelerates ER-associated degradation. EMBO Rep., 2, 415-422.

Jakob, C.A., Bodmer, D., Spirig, U., Bättig, P., Marcil, A., Dignard, D., Bergeron, J.J.M., Thomas, D.Y. and Aebi, M. (2001) Htmlp, a mannosidase-like protein, is involved in glycoprotein degradation in yeast. EMBO Rep., 2, 423-430.

Jakob, C.A., Burda, P., Roth, J. and Aebi, M. (1998) Degradation of misfolded endoplasmic reticulum glycoproteins in Saccharomyces cerevisiae is determined by a specific oligosaccharide structure. J. Cell Biol., 142, 1223-1233.

Kornfeld, R. and Kornfeld, S. (1985) Assembly of asparagine-linked oligosaccharides. Annu. Rev. Biochem., 54, 631-664.
Liu, Y., Choudhury, P., Cabral, C.M. and Sifers, R.N. (1997) Intracellular disposal of incompletely folded human $\alpha 1$-antitrypsin involves release from calnexin and post-translational trimming of asparagine-linked oligosaccharides. J. Biol. Chem., 272, 7946-7951.

Nakatsukasa, K., Nishikawa, S., Hosokawa, N., Nagata, K. and Endo, T. (2001) Mnllp, an $\alpha$-mannosidase-like protein in yeast Saccharomyces cerevisiae, is required for endoplasmic reticulum-associated degradation of glycoproteins. J. Biol. Chem., 276, 8635-8638.

Parodi, A.J. (2000) Protein glucosylation and its role in protein folding. Аnnu. Rev. Biochem., 69, 69-93.

Su, K., Stoller, T., Rocco, J., Zemsky, J. and Green, R. (1993) Pre-Golgi degradation of yeast prepro- $\alpha$-factor in a mammalian cell. J. Biol. Chem., 268, 14301-14309.

\section{Ineke Braakman}

Department of Bio-Organic Chemistry, Utrecht University, Padualaan 8, $3584 \mathrm{CH}$ Utrecht, The Netherlands

Received April 11, 2001; revised June 20, 2001; accepted June 28, 2001

Tel: +31 30253 2759/2184; Fax: +31 30253 6900;

E-mail: I.Braakman@chem.uu.nl

DOI: $10.1093 /$ embo-reports/kve162 